\title{
Etika Profesi Teknologi Informasi Komunikasi Ditinjau Dari Sudut Pandang Ajaran Islam
}

\author{
Warsino ${ }^{1)}$, Yahya Mara Ardi ${ }^{2)}$ \\ Program Studi Sistem Informasi, Universitas Bina Sarana Informatika, \\ Jl Kamal Raya 18, Ring Road Barat, Cengkareng, Jakarta \\ e-mail: warsino.war@bsi.ac.id ${ }^{1)}$, yahya.yym@bsi.ac.id ${ }^{2)}$
}

(artikel diterima: 08-05-2020, artikel disetujui: 12-07-2020)

\begin{abstract}
Abstrak
Ilmu pengetahuan dan teknologi berkembang sangat pesat. Komputer dan internet menjadi bagian yang tidak terpisahkan dari perkembangan teknologi ini. Salah satu tantangan yang dihadapi dalam pesatnya teknologi informasi adalah masalah etika. Tulisan ini menjelaskan bagaimana Islam sebagai ajaran yang paripurna mampu memberikan solusi atas problematika yang dihadapi berkaitan dengan masalah etika. Aspek etika terdiri atas privacy, accuracy, property dan accessibility, semua ada petunjuknya dalam Islam, baik dari Al Quran maupun Hadits Nabi Muhammad SAW. Setelah membaca tulisan ini, muslim sebagai mayoritas penduduk Indonesia akan semakin bijak dan menjunjung tinggi etika sebagai bagian dari pengabdian dan ketaatan kepada Allah SWT.
\end{abstract}

Kata kunci: etika, islam, profesi, TIK

\begin{abstract}
Science and technology develop significantly. Computer and internet become integral part of this technology development, particularly in information technology. One of the challenges should be faced in this fast development of information technology is ethical issue. This article explains that Islam as comprehensive teachings is able to provide solutions for any problems in relations to ethical issue. Aspects of ethical issue, which consist of privacy, accuracy, property, and accessibility, are entirely contained in the main teaching sources of Islam, namely the Qur'an and Hadith. After reading this article, Muslims as the majority population in Indonesia may be wiser and utilize ethics as part of their worships and obedience to Allah the Great
\end{abstract}

Keywords: etika, etika islam,profesi, TIK

\section{PENDAHULUAN}

Indonesia negara dengan jumlah penduduk yang beragama Islam terbesar di dunia. Berdasar data yang di rilis oleh The Global Religious Future, pada tahun 2020 ini, jumlah muslim di Indonesia sebesar 229,6 juta jiwa (Anon., 2020). Dengan populasi yang sedemikian besarnya, maka muslim mempunyai peranan yang sangat besar terhadap pemanfaatan teknologi informasi yang juga berkembang sangat pesat di Indonesia. Sebuah study yang dilakukan oleh Wearesocial, pengguna internet di Indonesia berjumlah 150 juta orang, dengan rata-rata menghabiskan waktu 8 jam 36 menit per hari (Anon., 2020). Berkembang sangat pesat dibandingkan pengguna pada tahun 1998, yang berjumlah hanya 500 ribu orang. Hal ini menjadi perhatian serius semua pihak, mengingat keterhubungan antar manusia memungkinkan mereka untuk melakukan banyak kegiatan, seperti berbagi informasi, transaksi perniagaan, belajar, mengekspresikan ide dan gagasan serta banyak ragam aktivitas yang bisa dilakukan. 
Inilah yang oleh para pakar disebut era industry 4.0. Era dimana sistem komputer berbasis Artificial Inteligence dan Robotika. Tak ada lagi batas-batas geografis. Semua terhubung dalam sebuah jaringan raksasa yang bernama internet. Dunia internet sama halnya dengan dunia nyata, terdiri atas beragam pengguna, yang berbeda latar belakang suku, agama, ras, kebangsaan, sosial ekonomi dan lain-lain. Dengan kompleknya pengguna internet tersebut, agar semua penguna internet merasa nyaman, maka diperlukan tatanan yang harus dihormati dan dijunjung tinggi oleh semua pengguna internet. Untuk itu, satu hal penting yang harus diperhatikan adalah masalah etika.

Etika berarti watak kesusilaan atau adat kebiasaan (Aziz, 2010). Etika bisa dijadikan sebagai acuan untuk mengatur, bagaimana seorang professional memberikan kontribusi dalam menjalankan profesinya. Dengan etika ini, maka seorang praktisi TIK bisa menganalisa, perilaku seperti apa yang boleh dikerjakan, dan perilakau apa yang tidak boleh dikerjakan. Banyak literatur yang menjelaskan tentang pentingnya etika. Sebagian besar, literature ini berasal dari barat. Islam sebagai sebuah ajaran agama sempurna, didalamnya mengatur seluruh kehidupan pemeluknya. Nabi Muhammad sebagai pembawa risalah Islam, diutus untuk memperbaiki akhlak manusia. Di sini, fungsi Islam menjadi pedoman perilaku kehidupan pemeluknya, termasuk bagi professional praktisi TIK. Islam menjadi pemandu, apa saja yang boleh dikerjakan, dana pa saja yang tidak boleh dikerjakan.

Ada beberapa peneliti yang menulis bagaimana Islam menjadi solusi bagi permasalahan etika dalam dunia TIK. Diantaranya Salam Abdallah dari Abu dhabi University, Wazir Zada Khan dari Jazan University KSA. Tulisan ini bertujuan untuk melihat beberapa kaidah dalam Al Quran maupun Hadits Nabi Muhammad SAW, dalam kaitannya dengan etika bagi professional TIK, dengan harapan akan semakin terbuka pemahaman para pelaku atau professional TIK bahwa Islam mengatur aspek moral dan mempunyai panduan dalam menggunakan teknologi informasi.

\section{METODE PENELITIAN}

Penelitian adalah cara ilmiah untuk mendapatkan data dengan tujuan dan kegunaan tertentu. Sebagai sebuah karya ilmiah, penelitian harus memiliki ciri-ciri keilmuan, diantaranya rasional, empiris dan sistematis (Sugiyono, 2010). Untuk mendukung agar penelitian ini sesuai kaidah ilmiah, maka penulis menggunakan data sekunder dengan metode observasi dan studi pustaka untuk mendapatkan data guna menyusun tulisan ini. Beberapa jurnal, baik yang dipublikasikan di Indonesia maupun di manca negara menjadi sumber rujukan. Selain itu, ada pula beberapa buku dan situs, yang berkaitan dengan etika penggunaan komputer maupun Al Quran dan Hadits menjadi bahan studi pustaka yang dipelajari dan diperiksa dengan cermat.

\section{HASIL DAN PEMBAHASAN}

\subsection{Konsep Etika}

Kata "etika" berasal dari Bahasa Yunani "ethos", yang berarti "kebiasaan". Dalam Kamus Besar Bahasa Indonesia, etika adalah ilmu tentang apa yang baik dan 
apa yang buruk dan tentang hak dan kewajiban moral/akhlak. (Indonesia, 2020). Banyak studi yang membahas tentang etika. Meskipun awalnya hanya dipelajari dalam bidang filsafat saja, namun saat ini hampir semua bidang menjadikan etika sebagai salah satu bagian dalam pembelajaran. Jenis-jenis teori etika yang paling umum adalah konsekuensi deontologis dan categorical (Abdallah, 2010). Teori etika ini berdasar pada penentuan perumusan daftar aturan atau prinsip yang menentukan atau menilai sesuatu itu benar atau salah, boleh atau tidak dan seterusnya.

\subsection{Etika Profesi Teknologi Informasi dan Komunikasi Dalam Sudut Pandang Ajaran Islam}

Semua aspek dalam ajaran agama Islam didasarkan pada hukum yang bersumber dari Qur'an, Hadits, Ijma, Qiyaz (Khallaf, 2003). Dalam konsep etika, Islam mengenal istilah "akhlak". Akhlak berasal dari kata "khuluq". Dalam Al Quran, kata "khuluq" bisa ditemukan dalam:

a. Q.S Asy Syuara : 137

Artinya, "Agama kami ini tidak lain hanyalah adat kebiasaan orang terdahulu."

Dalam Tafsir Ibnu Katsir disebutkan bahwa frasa Khuluqul Awwalin artinya agama mereka dan tradisi yang biasa mereka lakukan adalah adat kebiasaan orang-orang terdahulu dari kalangan nenek moyang mereka. Sedangkan Imam Qurthubi menafsirkan bahwa Khuluqul Awwalin adalah adat istiadat kuno dan termasuk juga didalamnya agama, karakter, ideologi maupun doktrin. Imam Al Ghozali mendefinisikan bahwa moralitas lebih penting dari kebiasaan (Asadullah, et al., 2014) .

b. Q.S Al Qolam : 4

Artinya, "Dan sesungguhnya, kamu benar-benar berbudi pekerti yang agung." Imam Ibnu Katsir menuliskan dalam kitab tafsirnya berdasarkan banyak hadits, bahwa Rasulullah Muhammad SAW memiliki akhlak sebagaimana dalam Al Quran, mengamalkan perintah-Nya, menjauhi larangan-Nya, telah tertanam dalam diri beliau watak dan pembawaan yang telah terpatri dalam sepak terjangnya (Asadullah, et al., 2014).

Dengan terminologi akhak seperti diatas, dimana umat Islam harus berakhlak sesuai Al Qur'an, menjalankan semua perintah-Nya dan menjauhi semua laranganNya, maka etika dalam Islam (akhlak) akan menginspirasi umat Islam untuk menjalankan seluruh aspek kehidupannya sebaik mungkin, termasuk dalam menjalankan pekerjaan yang berkaitan dengan komputer dan semua teknologi yang terkait.

Dalam menggunakan komputer, pengguna komputer harus memperhatikan dengan sungguh-sungguh beberapa aspek utama dalam penggunaan computer tersebut. Aspek aspek utama dalam penggunaan komputer, sebagimana disebutkan Manson, terdiri atas Privacy, Accuracy, Property dan Accesibility (Brown, 2018). Sampai saat ini konsep ini masih relevan. Issue lain yang berkaitan dengan etika computer antara lain: pemanfaatan waktu, kejujuran, integritas, hak atas kekayaan intelektual dll (Muhammad Masum, 2013). 


\subsubsection{Privacy}

Di era e-commerce sekarang ini, aspek privacy menjadi sesuatu yang sangat penting untuk menjadi perhatian utama. Banyak aplikasi pembelian online yang mensyaratkan calon pembeli untuk mengisi data pribadi. Bagi sebagian orang, data pribadi belum merupakan hal yang penting untuk dilindungi. Akan tetapi, mengingat internet adalah media lintas negara, maka data pribadi menjadi sesuatu yang sangat penting untuk dilindungi, agar tidak disalahgunakan oleh orang-orang yang tidak bertanggung jawab. Banyak kejahatan bidang komputer yang dimulai dari pencurian data-data pribadi. Orang yang tidak bertanggungjawab mungkin akan mengambil, mengeksplorasi, menyalahgunakan, menyebarkan informasi yang sifatnya sangat pribadi. Dalam Islam, semua yang sifatnya pribadi sangat dihargai. Ada beberapa petunjuk baik dalam Al Quran maupun Hadits, diantaranya:

- Al Quran Surat An Nur ayat 27, yang artinya, "Hai orang-orang beriman, janganlah kamu memasuki rumah yang bukan rumahmu, sebelum meminta izin dan memberi salam kepada penghuninya. Yang demikian ini lebih baik bagimu, agar kamu selalu ingat."

- Al Quran Surat Al Hujurat ayat 12, yang artinya, “ Hai orang-orang yang beriman, jauhilah kebanyakan pra sangka (kecurigaan), karena sebagian dari kecurigaan itu dosa."

- Hadits Bukhari No 5143, "Waspadalah terhadap buruk sangka, karena buruk sangka adalah sejelek-jelek perkataan dusta."

\subsubsection{Accuracy}

Informasi yang dihasilkan atau didistribusikan harus mempunyai kualitas yang baik. Informasi dikatakan baik, jika memiliki 3 aspek, yaitu akurat, tepat waktu dan relevan. Setiap informasi yang dihasilkan harus benar-benar sesuai dengan kenyataannya. Informasi tidak boleh bias, berkurang atau bertambah. Tidak boleh juga informasi yang dikirim oleh pengirim ke penerima terjadi modifikasi atau perubahan. Informasi yang tidak tepat tidak bisa digunakan untuk menghasilkan keputusan. Islam memandang etika dalam menyampaikan informasi adalah suatu hal yang harus dijunjung tinggi (Amril, 2017). Kebohongan dan ketidakakuratan sebuah informasi bisa menyebabkan kehancuran baik pribadi maupun sebuah bangsa. Dalam sejarah pernah terjadi suatu kejadian yang dikenal dengan peristiwa Haditsul Ifki, peristiwa dimana ada informasi bohong tentang istri Rasulullah, yaitu Aisyah RA yang disebarkan oleh orang-orang munafik. Dalam Al Quran landasan yang bisa dijadikan acuan yaitu Q.S An Nur ayat 15, yang artinya, "ingatlah diwaktu kamu menerima berita bohong itu dari mulut ke mulut dan kamu katakan dengan mulutmu apa yang tidak kamu ketahui sedikit juga, dan kamu menganggapnya suatu yang ringan saja. Dan dia pada sisi Allah adalah besar." Secara umum, etika pemberian informasi dalam Al Quran, yaitu: jujur, adil, akurat, dan tidak berbohong (Amril, 2017). Jadi dalam sudut pandang Islam, akurasi merupakan salah satu bagian dari etika pemberian informasi. 


\subsubsection{Property}

Property berkaitan dengan hak milik atau kepunyaan seseorang terhadap sesuatu secara eksklusif. Saat ini, yang menjadi fokus penting dalam etika penggunaan komputer adalah property yang berkaitan dengan HAKI (Hak Atas Kekayaan Intelektual) (Aziz, 2010). Kepemilikan intelektual dianggap sebagai kekayaan yang tidak berwujud, yang merupakan karya dari pribadi atau organisasi, yang dilindungi baik itu hak cipta, paten, maupun rahasia perdagangan. Karya-karya tersebut bisa berupa perangkat lunak, e-book, lagu dan lirik, ide maupun produkproduk hasil olah fikir dan kreasi yang tidak berwujud benda. Internet dan teknologi informasi membuat perlindungan terhadap produk tersebut sulit untuk dilindungi kepemilikannya, karena mudahnya disalin dan didistribusikan (Muhammad Masum, 2013). Dalam ajaran Islam, kepemilikan menjadi sesuatu yang sangat dihormati. Dalam Islam, dikenal istilah Dharuriyyatul Khams, yang artinya lima hal penting yang harus dijaga dari seorang muslim. Kelima hal tersebut adalah agama, jiwa, akal, keturunan dan harta. Seseorang yang mencuri atau mengambil harta atau kepunyaan orang lain secara sembunyi-sembunyi tanpa izin, bisa dikenakan hukuman sariqah (Irfan \& Masyrofah, 2014) .

Islam sangat menganjurkan umatnya untuk beramal, belajar dan bekerja. Namun, dalam melaksanakan aktivitas tersebut harus dengan proses dan metode yang baik. Alat dan media yang digunakan juga harus terjamin bukan dari hasil perbuatan jahat dan melanggar hukum. Oleh karena itu, segala bentuk perbuatan melanggar hukum dalam penggunaan komputer, baik berupa plagiarisme, pencurian data, mengutip tanpa izin dan lain-lain dilarang. Islam menganjurkan agar setiap orang yang menggunakan kepunyaan orang lain untuk meminta izin terlebih dahulu sebelum menggunakannya.

Beberapa dalil yang berkaitan dengan kepemilikan ini antara lain:

- An Nisa ayat 29, yang artinya, "Hai orang-orang yang beriman, janganlah kalian saling memakan harta sesama kalian dengan jalan yang batil, kecuali dengan jalan perniagaan yang berlaku dengan suka sama suka diantara kalian." Dalam tafsir Ibnu Katsir dijelaskan bahwa Allah SWT melarang seorang hamba yang beriman memakan harta dengan cara yang batil, yaitu usaha-usaha yang tidak diakui secara syariat (Khallaf, 2003).

- Hadits Bukhari No 6810 dan Muslim No 57, yang artinya, "Tidaklah beriman seorang pencuri ketika ia sedang mencuri."

Bagi orang Islam yang melakukan kejahatan mengambil hak atau property orang lain tanpa izin, maka berlaku baginya Jarimah Ta'zir, yaitu hukuman yang tidak disebutkan kadar hukumnya oleh syara', dan menjadi wewenang dari hakim atau penguasa (Irfan \& Masyrofah, 2014).

\subsubsection{Accesibility}

Dalam konsep akses, fokus utama aspek etika penggunaan komputer adalah tersedianya akses untuk semua kalangan dan bagaimana biaya yang muncul atas akses tersebut, namun terjamin keamanannya baik dari sisi pemberi dan penerima informasi. Dengan demikian, hadirnya teknologi informasi bukan menjadi halangan terhadap individu, kelompok atau organisasi tertentu, namun akan sangat mendukung 
bisa diaksesnya suatu informasi untuk semua pihak (Aziz, 2010). Dalam era informasi 4.0 seperti saat ini, kebutuhan akan informasi dan kemampuan mendapatkan data menjadi sangat penting. Namun perlu diingat pengguna informasi harus terlebih dahulu mempunyai kemampuan mengakses secara fisik untuk mendapatkan sumber daya informasi. Selanjutnya, yang lebih penting adalah mereka harus bisa mengakses informasi itu sendiri. Dalam hal ini, kemampuan akses berkaitan erat dengan kepemilikan atau property dan keamanan (Alexandra, 2020). Dalam kaitan antara hak akses dengan masalah keamanan, maka Islam memberikan rambu-rambu yang jelas yang bisa dijadikan pedoman oleh pemeluknya. Beberapa kisah dalam Al Quran yang dijadikan rujukan dalam masalah keamanan diantaranya sebagai berikut:

- Surat Al Kahfi ayat 90 - 98. Ayat ini berkisah tentang Nabi Zulkarnaen AS dengan Ya'juj dan Ma'juj. Dikisahkan Nabi Zulkarnaen membangun dinding yang tebal dan tinggi, sehingga kaum Nabi Zulkarnaen terlindungi dari serangan Ya'juj dan Ma'juj. Benteng tersebut dibangun dengan menggunakan tembaga dan besi yang panas. Benteng dinding besi panas inilah yang kemudian kita kenal dalam keamanan internet sebagai firewall, yang mempunyai fungsi menghalangi akses bagi orang-orang yang tidak mempunyai otoritas dan berusaha masuk ke dalam sistem komputer.

- Surat An Naml ayat 20 - 21. Ayat-ayat dalam surat ini berkisah tentang informasi yang disampaikan oleh Burung Hud-Hud kepada Nabi Sulaiman tentang seorang ratu yang sangat disegani bernama Ratu Bilqis, yang menyembah matahari. Nabi Sulaiman tidak langsung mempercayai informasi tersebut, namun mengirimkan surat ke Ratu Bilqis. Prinsip inilah yang dalam dunia teknologi informasi disebut sebagai checking dan uji validitas (Soediro, 2018).

\section{KESIMPULAN}

Perkembangan ilmu pengetahuan dan teknologi telah menghasilkan kemajuan yang sangat pesat dalam dunia teknologi dan informasi. Di sisi lain, perkembangan pemahaman masyarakat tidak sebanding dengan cepatnya kemajuan teknologi tersebut. Islam yang telah hadir sejak 1400-an tahun yang lalu, mampu menjawab kebutuhan akan pentingnya etika dalam penggunaan teknologi komputer. Semua aspek yang berkaitan dengan etika teknologi komunikasi dan informasi bisa diselesaikan dengan pemahaman dan pengamalan ajaran Islam. Inilah yang disebut Islam sebagai sebuah ajaran yang syumuliyyah, yang artinya mengatur seluruh kehidupan manusia, baik sebagai pribadi, masyarakat, bangsa, negara dan seluruh aspek kehidupan manusia. 


\section{DAFTAR PUSTAKA:}

Aziz, K., 2010. Etika Profesi Dalam Dunia Bisnis Dan Teknologi Informasi. Jakarta: Pembelajar Presindo.

Asadullah, A., Yerima, B. \& Aliyu, Y., 2014. The Ethics of Information and Communication Technology: An Islamic Overview. International Journal of Information and Communication Technology Research, pp. 45 - 49.

Abdallah, S., 2010. Islamic Ethics: An Exposition For Resolving ICT Ethical Dilemmas. Journal of Information, Communication \& Ethics in Society, pp. 289-301.

Muhammad Masum, A. K., 2013. Ethical Issue in Computer Use: A Study from Islamic Perspective. Global Jurnal of Computer Science and Technology Interdiciplinary, pp. 5 - 11.

Sugiyono, 2010. Statistika Untuk Penelitian. Bandung: Alfabeta.

Anon., 2020. The Global Religious Future. [Online] Available at: http://www.globalreligiousfutures.org/countries/indonesia/religious_demogr aphy\#/?affiliations_religion_id=0\&affiliations_year=2020

Anon., 2020. We Are Social. [Online]

Available at: https://wearesocial.com/global-digital-report-2019

Khallaf, A. W., 2003. Ilmu Ushul Fikih. Jakarta: Pustaka Amani.

Ash Shabuni, M. A., 2016. Tafsir Ayat Ayat Ahkam. Depok: Keira Publishing.

Reynold, G., 2015. Ethics in Information Technology. Boston: Cengage Learning.

Leikas, J., Koivisto, R. \& Gotcheva, N., 2019. Ethical Framework for Designing Autonomous Intelligent Systems. Journal of Open Innovation, pp. 1 - 12.

Brown, K. C., 2018. A Consideration of Masons Ethical Framework: The Importance of PAPA Factors in The 21'st Century, Florida: University of North Florida.

Indonesia, K. $\quad$ B. $\quad$ B., 2020. Web: kbbi. [Online] Available at: https://kbbi.web.id/etika

Amril, D., 2017. Etika Informasi Dalam Perspektif Al Quran. Jurnal Al Fuad, pp. 54 $-68$.

Irfan, N. \& Masyrofah, 2014. Fiqh Jinayah. Jakarta: Amzah. 
Alexandra, J., 2020. Binus University. [Online] Available at: https://sis.binus.ac.id/2018/02/22/papa-privacy-accuracyproperty-and-accessibility/

Soediro, 2018. Prinsip Keamanan Privasi dan Etika Dalam Undang-Undang Informasi dan Transaksi Elektronik Dalam Perspektif Hukum Islam. Jurnal Kosmik Hukum, pp. 1 - 18. 